over, instead of removing a larger proportion of the thinner parts of the image, which, of course, lie near the surface of the film. This is an exceedingly useful effect; but here again the chemical changes have not been investigated, and the theories that have been suggested to account for the exceptional effect are far from satisfactory. It is not certain, indeed, that the remaining image is of pure silver.

The makers of apparatus are always seeking to improve their goods, and they are, as a rule, so successful that it is impossible to refer here to other than the most important advances. Photographers used to be satisfied with lenses that either covered a large field in proportion to their focal length, or that had a large aperture but these properties that used to be considered incompatible now have to be combined ; a large angle of view is maintained while the aperture is increased. Instead of $f / 8$, which used to be regarded as the maximum aperture for outdoor work, we now have $f / 6$, and even larger apertures, without the introduction of the peculiar faults usually associated with portrait lenses. The firm of Goerz, of Berlin, has quite lately put upon the market a doublet, each combination of which consists of five elements, the complete objective having an aperture of $f / 5.5$. These-the stigmatics of Dallmeyer at $f / 4$ and $f / 6$, the planars of Zeiss with apertures of about $f / 4$, and other lenses of similar properties-are instruments of precision for giving an image over an extended field, as telescope objectives are instruments of precision for giving definition over a very small field. In conjunction with the rapid gelatine plates of to-day, they place a power in the hands of scientific workers that was not conceived possible a few years ago.

The firm of Dallmeyer have recently improved their stigmatics, series $f 6$, by putting the combination of greater focal length in the front instead of behind. To use either combination alone, it is now only necessary to remove the other, and the extension of camera necessary is nearly the same for both the combinations, although their equivalent focal lengths are approximately as $I^{\prime} \cdot 5$ to 2 , taking the focal length of the whole combination as the unit. Dr. Rudolph, of Zeiss', has investigated the question of the use of cylindrical surfaces in objectives for the purpose of getting a different ratio of enlarge ment (or reduction) in two directions at right angles to each other. One result of this work is the "anamorphot" issued by Messrs. Zeiss, and its use is chiefly, if not exclusively, in the readjustment of the proportion of length to breadth of designs for their application in the decorative arts.

There does not appear to have been any radical improvement in cameras of late; but the system of cinematography, made possible by the perfection to which film-supported sensitive surfaces have been brought, continues to engage the attention of a large number of inventors. The most recent, and doubtless most interesting, application of this principle is in an apparatus that the Kodak Cornpany are making for Sir Norman Lockyer, for use during eclipses of the sun. The apparatus will accommodate a film five inches wide and of length suitable for the required series of exposures. The opening behind which the film is exposed is twelve inches long and three inches wide. The apparatus is designed to photograph a series of spectra, as of the chromosphere, so that the exposures may follow each other with greater rapidity and certainty than is possible when plate-changing has to be done by hand. The operator has only to turn a handle continuously, and at each complete revolution an exposure is made, the exposed film is wound up, and a new portion brought into position. Three-quarters of the revolution effects the change of film; at the beginning of the remaining fourth the shutter is opened; it continues open until the revolution is completed, or nearly completed, when it is closed; then the filmNO. 1583 . VOL. 61$]$ changing takes place again, and so on. By stopping the crank during the last quarter of the revolution, a timeexposure of any duration may be given. It is expected that the apparatus will be used in conjunction with a twenty-foot objective of six inches aperture with a prism in front of the objective ; and as this lens gives practically no curvature on a field twelve inches in length, the film will be used flat.

Scientific photographers on the Continent have lately been paying more attention to the measurement of the opacities of photographic plates. Dr. J. Hartmann, of Potsdam, has recently described an apparatus constructed for him for comparing opacities. It consists of a horizontal microscope with its ocular and objective, with a tube branching from it at right angles, downwards, that carries a second objective. At the junction of the two tubes is the well-known arrangement of two right-angled prisms, with their bypothenuse surfaces cemented together except at a small disc in the centre of the adjacent sides; so that one sees a small portion of the plate being tested surrounded by the comparison tint. The apparatus appears to be unnecessarily costly and complicated when compared with apparatuses that have been used in this country for a similar purpose.

There are many other matters that would claim attention in a complete résumé of recent progress in photography, some of which have already been referred to in these columns.

C. J.

\section{THE POSITION THAT UNIVERSITIES SHOULD TAKE IN REGARD TO INVESTIGATION.}

THE American Society of Naturalists arranged for a discussion on the duties of universities with regard to investigation, and the American journal, Science, has recently published the contributions to the discussion made in the end of last year at the New Haven meeting. Profs. Dwight of Harvard, Chittenden of Yale, Jastrow of Wisconsin, Patten of Dartmouth, and Dr. Macdougal of the New York Botanic Gardens---five distinguished representatives of the natural sciences in America-made a formal and deliberate expression of their opinions, and an examination of these convictions cannot fail to be valuable to English readers. On all salient points these experts are in complete agreement. They have no doubt that the connection between universities and research is fundamental. Dr. Macdougal dismisses it as "axiomatic." Prof. Jastrow declares that a university should be the "natural habitat" of investigation. Prof. Dwight is "sure of a sympathetic hearing from public and universities for discussion of the modes and conditions of university research." The others differ only in the precise phraseology they employ. Nor is there any doubt but that university teachers should be investigators by temperament and habit. As Prof. Chittenden insists, the primary function of a university is a diffusion of the knowledge already gained, rather than the provision of new knowledge ; but, although teachers who were not investigators have existed, the ideal teacher must be more than a diffuser. All universities of standing make success in investigation a necessary qualification for their teachers, and, in effect, our witnesses all agree that, having chosen rightly such men, it is the duty of the universities to see that time and opportunity for investigation should be found for them during their tenure of office.

There is a certain divergence of opinion as to the extent to which original investigation should be made an actual part of the training of students. Prof. Dwight and Prof. Patten are not inclined to encourage it, the former thinking chiefly of medical students and agreeing with Huxley, that whoever adds one tittle of what is unnecessary to medical education is guilty of a very grave 
offence, the latter disapproving of it entirely as a normal part of the curriculum. Others, again, incline to the view that actual new investigation, as opposed to ordinary laboratory work, is an extremely important and useful incident in training. On the other hand, there is no trace of difference of opinion as to whether or no it is not at once an imperative duty and an immense practical advantage for a university to provide every encouragement in the shape of equipment and scholarship or fellowship endowment for what may be called post-graduate research. In this respect the duties of a university are to be limited only by her resources.

The general result of this interesting discussion by experts is that an atmosphere of original investigation should pervade a university. Its professors must be investigators if only because otherwise they cannot be competent teachers. Its schools must be provided with the appliances and material facilities for research, and it must attach to itself by scholarships and fellowships numbers of young men devoting themselves, in the first place, to research ; while the conduct of original investigation may be made an incident in the normal training of advanced students.

It is to be noticed that this emphatic pronouncement is based directly on experience, and on experience of a strictly pedagogic or university type. These experts in conference had no need to raise the underlying principles on which useful continuance of the existence of universities depends. Universities are organs of the community, and the pabulum that they absorb, whether it be derived from hoards of the past or from the circulating wealth of the present, obviously is diverted from other uses. Their utility depends upon the returns they make to the community. Such products consist of an output of trained men and of knowledge; these, to resume the metaphor, corresponding to the direct secretion of an organ, and the general diffusion of a subtle but pervading influence comparable with the internal secretions discovered by modern physiology. A university that starves and discourages research turns out into the world smooth and conventional graduates, blind to the surprising novelties of life, more ready to meet crises, small or great, with historical parallels than novel efforts; fitter to adorn success than to achieve it; it prefers criticism to knowledge, style to matter, glosses and reconciliations to the disconcerting energy of new ideas; it instils into the body politic a bland and slothful miasma of selfcontent. A university pervaded by the spirit of investigation sends out graduates ready to change with changing conditions, to whom difficulties are opportunities, and who, above all, are trained to watch for the inevitable changes in the most familiar ideas as new facts creep into light ; it sends out the new knowledge, which becomes transmuted into new practical advantages for humanity, and it sends out the old knowledge not wrought into artificial harmonies, but with a bold presentation of the gaps and roughnesses which are the chief stimulus to new discovery; it radiates through the community the alert and adaptive spirit of progress.

It is needless to say that, like the American universities, the universities of the continent, and in especial those of Germany, are conspicuous for the extent to which they encourage research by their funds and by their arrangements. The historian of the future, who is to trace the vast progress made in recent years by Germany in power, wealth, commerce, the arts and industries, without doubt will notice the part played by her many universities in this momentous change. A single article in the pages of a scientific journal is not a suitable vehicle for any exact examination of the relative advances made by England and other countries in recent times. But, until matters have been put right, every opportunity is convenient to insist that the universities of Britain do not encourage research sufficiently, and that, in particular, her richest university habitually and systematically despises research in its general arrangements, in the allocation of its endowments, and in the distribution of its revenues. Moreover, it is especially unfortunate that not only is the amount of consideration given to research minute, but is diminishing.

A single example is more convincing than a multitude of general statements, and an appropriate instance lies unfortunately ready to hand in the preface to the last volume of "Linacre Reports," recently issued by Prof. Ray Lankester. The late Linacre Professor and present Keeper of the British Museum of Natural History, in a preface addressed to the Vice-Chancellor of the University of Oxford, deplores the attitude of the Oxford colleges to the natural sciences. "The College endowments," he states, and every one with knowledge of the matter is able to corroborate, "are now more largely than ever employed in maintaining a tutorial system, which is in itself of small value-if not positively injuriousand necessarily in complete antagonism to the development of the method of study, and to the wide range of subjects studied, which distinguish everywhere but in Oxford the University from the Preparatory School." Prof. Lankester believes that the natural sciences, the subjects particularly associated with research as a means of training and as a source of directive knowledge, should be supported by not less than two-thirds of the endowments at the disposal of these colleges. Oxford, no doubt, is an extreme example of the general failure of British universities to respond adequately to what everywhere but in England is regarded as the first duty of a university; but there is urgent need for inquiry into and redress of the conditions which have brought about the present state of affairs, and those institutions which have taken a larger view of their duties will be the first to approve a strong statement of the existing failure.

\section{BRITISH DRAGONFLIES.}

M R. LUCAS is favourably known to entomologists by previous works on British Butterflies and British Hawk-moths; but in the present work he has broken new ground, and gives us a complete and trustworthy account of our British Dragonflies, the study of which has previously been much neglected in England.

Dragonflies resemble butterflies in being among the largest and most conspicuous of day-flying insects; but they are far less numerous in species, for while there are 300 butterflies in Europe in round numbers, out of which from 60 to 70 inhabit the British Islands, the Dragonflies of Europe barely exceed 100, of which, however, 40 are admitted by Mr. Lucas as British, a considerably larger proportion than in the Butterflies. It is curious, however, that among seven additional species, properly excluded by Mr. Lucas as not truly indigenous, is Pantala flavescens, Fabricius, said to have been taken years ago by Sparshall in the Fens. This is an abundant species in nearly all parts of the world (Asia, Africa, Oceania and America), but with the single exception above-mentioned, it has never been noticed as occurring in any part of Europe.

One advantage of dealing with a limited subject is that it permits of its being treated with sufficient fulness for most practical purposes, in a sufficiently portable form.

While not neglecting the literature of his subject, a large portion of the present volume is based on $\mathrm{Mr}$. Lucas's own personal observations, which imparts much greater value to the whole of his work; for although every author must be more or less dependent on the observations of others as well as on his own, yet he is not

1 "British Dragonflies" (Odonata). By W. J. Lucas, B.A., F.E.S Illustrated with 27 Coloured Plates and 57 Black and White Engravings Pp. xiv + 356. (London: L. Upcott Gill, rgoo.)

NO. I $58_{3}$, vOL. 6I] 